\title{
HELPFUL PROCESSES IN PSYCHOLOGICAL THERAPY FOR PATIENTS WITH PRIMARY CANCERS: A QUALITATIVE INTERVIEW STUDY
}

\section{ABSTRACT}

Aims: The purpose of this study was to identify what patients with primary cancers found helpful in therapy. Method: In-depth qualitative interviews were conducted with eight patients who had completed a course of psychological therapy within an NHS psychology service for cancer. Data was analysed using thematic analysis. Results: The participants identified a range of helpful processes in therapy: talking and expressing their feelings to someone outside of the family; forming a relationship with their therapist; normalisation through the therapists' expert knowledge; problemsolving and CBT. Limitations: As with all qualitative studies, the small sample and size and dependence on participant recall limits generalizability of the findings. Implications: The findings of this study are consistent with a pluralistic perspective: that multiple therapeutic process -- aligned to a range of different orientations -- can be of value to patients with primary cancers. This supports the provision of a range of therapeutic interventions and strategies for this patient group.

Keywords: cancer patients, helpful factors, individual psychological therapy, pluralistic therapy, primary cancers

According to the National Institute of Health and Clinical Excellence (NICE, 2004), psychosocial interventions are important for enhancing coping and quality of life for patients with cancer, and a range of 'pure form' (i.e., single orientation) therapies 
have been shown to be effective. These include problem-solving therapy (Nezu et al, 2003), counselling (Manne, et al, 2007), psychoeducation (Fawzy et al, 1995), and relaxation (Luebbert, 2001). However, this evidence-base has significant limitations. For instance, Mooray et al (1998) found that cognitive-behavioural therapy (CBT) with cancer patients produced greater change than counselling, but the study was criticised as both interventions were carried out by the same CBT therapists and did not involve bona fide counsellors. Furthermore, in contrast to a pure form approach, National Institute of Health and Clinical Excellence (NICE, 2004) guidelines advise tailoring interventions in relation to patients' individual needs.

As well as looking at the effectiveness of pure form therapies, therefore, it may also be important to look at the particular components of therapeutic practice both within and across therapies - that may be associated with positive therapeutic change. However, only three studies have focused on the aspects of psychological therapies that people affected by cancer found helpful. Here, research has focused on patients with metastatic (secondary) cancers (MacCormack et al, 2001), cancer patients, family and friends (Boulton et al, 2001), and patients with chronic medical conditions including cancer (Agnew et al, 2011). The findings suggest that relationship factors were considered the most helpful by patients (MacCormack et al, $2001 \&$ Agnew et al, 2011), including the opportunity to talk with somebody outside the family who 'truly cared', being able to talk openly and honestly, being heard and understood. Patients also reported that they found it helpful to express feelings, and that this led to emotional relief (Boulton et al, 2001). Closely linked to this, the therapist's personal qualities were considered an important element of therapy, including their warmth, genuineness, trustworthiness, flexibility; and ability to show compassion, emotional strength and foster hopefulness (MacCormack et al, 2001). 
'Being with' and engaging on a 'human level' were also described as helpful (MacCormack et al, 2001), but specific therapeutic interventions were similarly described as being of value (Agnew et al, 2011), including relaxation exercises (MacCormack, 2011). Similarly, patients said that they valued hearing stories from other patients of dealing with cancer (MacCormack et al, 2001), and wanted advice on how to deal with specific medical situations (Boulton et al, 2001). Examining and understanding emotional responses was perceived as helpful as it led to feeling reassured that feelings were normal (Boulton et al, 2001 and Agnew et al, 2011). Finally, confronting the fear of death and working through powerful thoughts and feelings around it were considered as helpful, which led to coming to terms with cancer and recovering a sense of control (Boulton et al, 2001).

With respect to patients with specifically primary cancers (confined to the part of the body where the cancer started to grow first, Macmillan Cancer Support, 2013), Lederberg and Holland (2011) have pointed out that there may be distinctive psychological needs from those with secondary cancers (when primary cancer spreads to another part of the body). However, research has yet to be conducted in this area. Hence, the aim of the present study was to focus specifically on helpful factors in psychological therapies for patients with primary cancers.

\section{$\underline{\text { Methods }}$}

\section{Participants}

Eight participants took part in the research, all of whom had recently completed a course of therapy with a clinical psychologist at a NHS Psychology Service for Cancer. On average, they attended for twelve sessions of therapy. Six females and two males took part in the study, and they were between 36 and 61 years old (mean 
age $=50.25)$. All participants had primary cancers: three breast, two gynaecological, one colorectal, one bladder and one haematological. All patients had completed preand post-therapy Hospital Anxiety and Depression Scales (HADS). At the beginning of therapy, patients' levels of anxiety on the HADs were within the moderate to severe range (mean 13.6); and, in terms of depression, were within the mild range (mean 8.9). At end of therapy, scores for anxiety and depression on the HADS for all patients were within the mild to normal range (anxiety mean 8.4 and depression mean 2.7).

\section{Procedure}

Ethical issues for this research were carefully considered and ethical approval was granted by the NHS Ethics Committee.

Participants in this study had participated in psychological therapy with one of five clinical psychologists. Two of the psychologists were males and three were females; with one an assistant psychologist and one a trainee psychologist. Principally psychologists based their work on a scientist-practitioner model (Page \& Stritzke, 2006) which involves delivering psychological assessment, formulation and intervention in accordance with scientific evidence. The psychologists also based their work on NICE guidelines for cancer patients (2010) advising tailoring individual intervention depending on patients' needs. All psychologists practised from integrative standpoints, using a range of psychological methods including CBT, Cognitive-Analytic Therapy (CAT), and narrative therapy. The psychologists had worked in the psycho-oncology setting for between six months and six years.

At their penultimate and/or final sessions of therapy, patients were asked by their psychologists if they would like to take part in a research study looking at what 
they had found helpful and unhelpful in their therapy. The psychologists did not approach patients who were physically unwell or/and who they judged as too distressed to take part in interview procedures. Patients had a least a week to consider if they wanted to take part in the study and patients who did not want to take part in the research were not asked again.

Where patients indicated that they were interested in participating, they either met with the researcher (the first author) to go over the information sheet, or were sent the information sheet which explained the study to them, including confidentiality and its limits. Patients were assured that their decision to participate or not participate would, in no way, affect their future care; and that only general research finding would be made available to their psychologist. Where patients agreed to participate, the researcher arranged with them a convenient time and place to conduct the interview. Prior to the interview, participants were invited to sign a consent form indicating that they understood, and agreed to, the study procedures.

The interviews were semi-structured and based on Elliott's (1989) Client Change Interview. This explored patients' experience of the therapy and the therapist; the ways in which the therapy was helpful; the goals that the patients had for therapy; and what had helped them achieve each goal and why. Unhelpful processes were also explored, although for reasons of space this is not reported here. The questions were paraphrased and adapted appropriately to the dialogues with each participant. The style of the interview was kept open, dialogical and aiming to explore the issues at depth (see Kvale, 1996). The interviews were digitally recorded.

\section{Analysis}


The interviews were transcribed, anonymised, and the recordings were erased following the transcription. Each participant was given a pseudonym.

The participants' responses were thematically analysed by the first author (Braun and Clarke, 2006) and sorted into categories and sub-categories, organised into four over-arching domains. These domains were: 1 . What the patients wanted to talk about; 2. Helpful activities: divided into what the patients felt that they did that was helpful (client activities), and what the patients felt the therapists did that was helpful (therapist activities) (see Cooper and McLeod, 2011); 3. The reasons that these activities were helpful (i.e., what they achieved); and, 4. The outcomes of these helpful activities in terms of psychological wellbeing. These domains, categories and sub-categories were then summarised in both narrative and table format.

In addition, a process map of the results was created (Cooper, 2012). This is a visual diagram which attempts to depict the prevalence of different categories; as well as their inter-relationships, and hence convey something of the process of change as well as its content. This process map went through several configurations in dialogue between the first and second author; and, after an extended process of categorising, re-categorising, checking and re-checking, was finalised. The prevalence of responses on the map is depicted through the size of the text, which is proportional to the number of respondents coded within that category. Links between different categories are represented only tentatively as most of themes had impact on each other.

\section{Reflexive statements}

The first author is a chartered counselling psychologist who works for the NHS psychology service for cancer patients using primarily person-centred practice but also other approaches such as CBT and psychodrama. In terms of her biases, she believes that the therapeutic relationship is a key element of therapy but patients may 
also need other things such as understanding of an underlying emotional pattern or learning new coping skills. The second author is a counselling psychologist with limited experience of working with cancer patients. He has tended to emphasise the importance of relational factors in therapeutic change (see, for instance, Mearns and Cooper, 2005); but also believes that different clients are likely to benefit from different therapeutic processes.

\section{$\underline{\text { Results }}$}

A summary of the thematic analysis is presented in Table 1. This is re-presented in diagrammatic form in Figure 1 as a process map.

[INSERT TABLE 1 ABOUT HERE]

[INSERT FIGURE 1 ABOUT HERE]

\section{What did cancer patients want to talk about?}

All patients wanted to talk about overwhelming feelings and adjustment issues. In terms of overwhelming feelings, patients mostly wanted to talk about feeling vulnerable and frightened. Liz said for example "I felt I must have saved up all of the emotional stuff. Where I should have been higher on my emotional scale, I wasn't and I felt it is not right". Adjustment issues included loss (of confidence, femininity and healthy self) and fear of cancer recurrence: "oh my God I have this dreadful pain in my side, it can only be one thing..." (Sandra). Following discussions around cancer recovery, five patients wanted to talk about other longstanding issues like Molly said “I would have never dreamt about sharing something about my past. I didn’t even 
know there was so much anger there...obviously it must have built up from when I was diagnosed with cancer..."

\section{What was helpful?}

\section{Patients' activities.}

Talking. This was identified as helpful by all patients. Expressing was the most helpful aspect of talking, which led to relief and gaining self-insight. For instance, 'Every time I came [to therapy] I would not shut up and...if I haven't have had that where would have all these words have gone?' (Sally).

Patients' own motivation. All patients identified that, in order to change, they needed to fully engage and participate in the therapeutic process. This involved getting though difficult situations/feelings and following through the therapy steps or plans. This led to gaining self-insight and developing strategies to deal with distress. For instance, 'An exercise that she gave me, obviously I had to do it myself, I had to take it home and think about how I deal with that anger' (Molly).

\section{Therapists' activities.}

Connection outside family. Patients said that they found it difficult to talk to family members as they did not want to burden/upset them or feel judged. They found it helpful to talk to somebody outside especially in terms of overwhelming feelings. For instance, Sally said of her family: 'They might have said "you are here and that's the important thing". I am here but it is not sorted... but I couldn't say that because it sounded selfish and could say it to the psychologist.'

Relational skills. The ability to build a therapeutic alliance was seen as important which included the therapist being approachable and easy to talk to. Donna 
said 'It never felt that I am sitting here with the therapist; it felt that I was having a coffee with a friend'. The therapist's non-judgemental attitude was also mentioned as a factor which helped patients to express themselves. Patients said that it was important that that they were treated on a personal level and not as a cancer issue. Sally said, 'I found that in therapy-- the one to one-- as opposed to "you are a patient number"... I felt as though we had a personal connection.'

Core therapeutic skills. The most helpful core therapy skill was encouraging the patient. Donna said: 'I went back to square one and I saw the psychologist afterwards ... "I can't do it...I fell off the balancing beam." And she said, "so what [do] people usually do?" [I said] "they go on the beam and they start again"... so she said "Right, that's what we are going to do".' Another core therapist skilled reported as being helpful was reassurance. Sandra said: 'I started most of my sentences [with] "this is going to sound absolutely stupid," and she would say, "no," and she would explain why'. Additionally patients stated that being asked questions helped them to express themselves, and also being listened to and having the things they said reflected back.

Cancer knowledge. The psychologist's knowledge of the emotional processes of adjustment following cancer diagnosis and treatment was perceived as being of crucial importance to all participants, especially when talking about overwhelming feelings and adjustment issues. This included understanding of medical information. It helped patients to realise that their feelings and difficulties were normal and understandable and that they were part of an adjustment process: 'She was accepting and made me see that a lot of it was very understandable... normal... not odd' (Sally).

Problem-solving. This was mentioned as helpful with overwhelming feelings and adjustment issues. It involved discussing strategies to manage fear of cancer 
coming back, getting back to work, weight management, sleep issues, communication and other family issues. Patients reported that problem-solving activities helped them to learn specific strategies to address their difficulties.

CBT techniques. Patients described the value of using CBT techniques in relation to overwhelming feelings (e.g., managing fear of cancer coming back), as well as in addressing non-cancer issues (e.g., panic attacks and health anxiety). Techniques included identifying and challenging distressing thoughts, identifying dysfunctional thinking styles (especially catastrophising), activity scheduling, and gradual exposure.

Other skills. Formulation, linking overwhelming feelings, adjustment and non-cancer issues was seen as helpful, especially for gaining self-insight.

Bibliotherapy on issues such as managing anger/ frustration and anxiety was reported as helpful in gaining understanding and learning to deal with distressing thoughts and feelings. Patients indicated that breathing techniques for relaxation were helpful in reducing distress. Writing a letter to a person from childhood was described as a release which helped to deal with a past issue.

Psychologist's gender. Two male patients reported that it was helpful that the therapist was male. This involved sharing a male solution-oriented approach for one patient, and challenging a view about men as abusers for another. A female patient mentioned that working with a female therapist helped her to not feel embarrassed when discussing 'female type' cancer.

\section{Why were these processes helpful?}

\section{Normalising.}


All patients said normalising was the most helpful aspect of therapy, helping them to realise that the emotions and difficulties they were experiencing were part of a natural adjustment process following cancer diagnosis and treatment. Alec said "you think what's wrong with me...the therapy has helped with that...it became clear by the discussions... that I am not alone in this situation...the psychologist has seen people in a similar situation before"

\section{Understanding.}

All patients reported that they gained understanding in therapy, which helped in dealing with their distress. This included self-insight about issues such as using cutting as a childhood coping mechanism, a pattern of bottling feelings up, and how current anger related to a patient's childhood trauma. This category also included becoming more self-aware: being more in touch with feelings (e.g. anger) which helped towards being more self-accepting. Sandra, for instance, reported, 'I have gone through that experience and I am not the same... I've realised... my husband and I we... just rolled along for years... that's [not] good enough.'

\section{Relief.}

Patients found that talking about feelings brought relief, which they described as getting feelings out of the system, offloading, unburdening, getting rid of anger and feeling purged.

\section{Empowering.}

Patients found that therapy had an empowering effect, as they said it was making them stronger and more confident as they achieved things and dealt with difficulties. 
Dan said: 'It was just the steps that we had, different goals... it was... building the confidence.'

\section{Reassuring.}

Patients reported that the therapy had a reassuring effect, including finding out that their feelings were normal and the recovery process will take a while. Patients felt reassured about their ability to cope and that there was help available. They learnt specific strategies to calm themselves and felt supported in the things they were doing. Liz said: 'It was nice to talk it through...if I was going about things in the wrong way...the psychologist would have said; but she supported me throughout.'

\section{Coping strategies.}

Patients reported that learning specific coping strategies in therapy was helpful including strategies to control panic, using a 'distress ladder' to know when to talk to family, how to communicate when feeling angry, having a plan when concerned about cancer coming back; and having strategies to calm themselves when distressed/ worried.

\section{Helpful outcomes}

\section{Distress reduced.}

As a result of therapy all patients said they were able to deal with distressing thoughts and feelings in better ways. This involved, for example, no longer 'beating themselves up', letting worrying thoughts come and go, no longer worrying about trivial things, reassuring themselves when scared, and being able to pinpoint feelings (e.g. anger or anxiety) and deal with them. 


\section{Moving on.}

Patients said that, as a result of therapy, they were able to move on, which included learning self-care skills (e.g., giving time to self, accessing support); improving relationships (e.g., being more assertive, not blaming partner); getting back to work and activities; reflecting on life priorities (e.g., revisiting life/work balance); regaining identity (e.g. a sense of femininity); and gaining confidence to look to the future again.

\section{Discussion}

The results of this study indicate that patients with primary cancers found a variety of processes helpful in their therapy. These were not limited to any one, orientation-specific understanding of therapeutic change but, as with previous research (Agnew et al., 2011; Boulton et al., 2001; MacCormack et al., 2001), suggest that methods and practices from a range of orientations can be of value to this patient group. Consistent with a person-centred/humanistic understanding of therapeutic change (e.g., Rogers, 1957), for instance, patients said that it was very helpful in therapy to have space to talk and express themselves, to engage with a therapist who was relationally skilled and non-judgemental, and to be motivated and agentic themselves (cf., Bohart and Tallman, 2001). Yet, less consistently with a personcentred/humanistic perspective, patients also emphasised the helpfulness of reassurance and of normalisation, and of working with a therapist who had a specific knowledge of psychological adjustment processes following cancer diagnosis and treatment, along with specific medical information. Furthermore, participants described the value of such cognitive-behavioural practices as problem-solving, 
relaxation techniques, formulation, and the use of self-help materials. Finally, consistent with a more psychodynamic perspective, participants described the value of gaining self-understanding.

While evidence-based guidelines, usually, tend to focus on the value of discrete, orientation-specific practices; the results of this qualitative investigation suggest that change, as experienced by patients with primary cancers, is not definable by any one model of therapeutic change alone. Rather, as with previous studies of patients' experiences (e.g., Clarke, Rees \& Hardy,2004), the results provide strong support for a pluralistic perspective (Cooper \& McLeod, 2007, 2011, 2012), which suggests that multiple change processes can take place in therapy, and that clients can be helped by interventions from a wide range of different orientations.

\section{$\underline{\text { Limitations }}$}

A key limitation of this study is that the results are entirely dependent on the patients' capacities for recall, and also to be able to know what is actually helpful for them. There is the possibility, then, that what is 'genuinely' helpful for patients is very different to what they have articulated here. The small sample size also makes generalisations of helpful processes more difficult. As with other studies of helpful factors, the responses that participants gave in this research were heavily dependent on the kinds of interventions they had participated in. All participants were seen by one group of therapists; clinical psychologists and had they been seen by other kind of therapists, a psychodynamic counsellor, for instance, they may have placed more emphasis on the value of such processes as 'interpretations' or 'working in the hereand-now'. The subjective bias of the authors and analyst of the data also mean that these may have been interpreted in a more pluralistic direction. 


\section{$\underline{\text { Implications for practice }}$}

In terms of implications for practice and training, the results provide a valuable guide to the therapeutic practices that may be of help for patients with primary cancers. It suggests that it is important for psychological therapists to provide them with an opportunity to talk and express themselves, and to relate to them in a non-judgemental and caring way, in which they are not just treated 'as a cancer issue'. At the same time, being more active and guiding in the therapeutic relationship seems to be helpful for many clients: providing reassurance and encouragement, and utilising CBT methods as well as problem-solving and formulation. The research also provides a strong indication that therapists working with this patient group should have a good working knowledge of cancer-related issues and the adjustment process, so that they can help their patients normalise their experiences, and develop a greater understanding of their issues.

\section{Conclusion}

Patients with primary cancers described a range of processes that were helpful in their therapy. These did not fit into any single model of therapeutic change; rather, they suggest that clients from this group can benefit from a range of different practice components. Patients wanted to address such overwhelming feelings as fear and anger, to adjust to their life circumstances, and also to explore non-cancer issues, such as relationship issues. To do this, they found it very helpful to talk and express themselves, drawing on their own motivation and resources. Therapists were described as being helpful in supporting this process through a supportive relational style, but also through using specific techniques and exercises. This led participants to 
feel more normal, relieved and aware of themselves; which, ultimately, led to moving on from feelings of distress and readjustment to life.

Although qualitative research into helpful processes is limited by the subjective perceptions of its participants, it has the potential to provide a very valuable guide to practice. Further studies of this type - combined with more quantitative evaluations of process-outcome relationships - can help to develop a greater understanding of what works for this - and other -- client groups.

\section{Acknowledgements}

The authors would like to thank the participants and professionals who supported and contributed to the research.

\section{References}

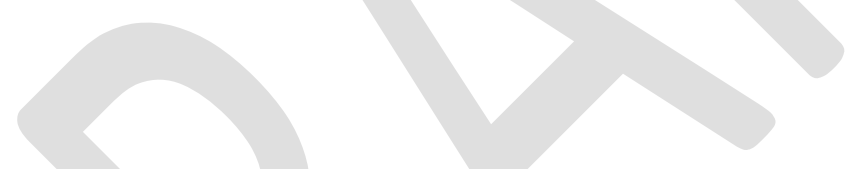

Agnew, F., Crossan, A., Davies, M., Hanna, D., Johnston, B., McClements, R. \& Tsang, S-M. (2011) What does 'client centredness' look like to clients? Clinical Psychology Forum. 222.

Bohart, A.C. \& Tallman, K. (1999) How Clients Make Therapy Work: The Process of Active Self-Healing. Washington DC: American Psychological Association.

Boulton, M., Boudioni, M., Mossman, J., Moynihan, C., Leydon, G. \& Ramirez, A. (2001) 'Dividing the desolation': clients views on the benefits of a cancer counselling service. Psycho-Oncology 10, 124-136

Braun, V. \& Clark, V. (2006) Using thematic analysis in psychology. Qualitative Research in Psychology, 3(2), 77-101. doi: 10.1191/1478088706qp063oa 
Clarke, H., Rees, A., \& Hardy, G. E. (2004). The big idea: Clients' perspectives of change processes in cognitive therapy. Psychology and Psychotherapy: Theory Research and Practice, 77(1), 67-89.

Cooper, M. \& McLeod (2007) A pluralistic framework for counselling and psychotherapy: Implications for research. Counselling and Psychotherapy Research. 7(3), 135-143.

Cooper, M. \& McLeod, J. (2011) Pluralistic Counselling and Psychotherapy. London: Sage.

Cooper, M. (2012). 'Process mapping: Representing multiple change experiences in counselling and psychotherapy,' UKCP Annual Research Conference, London.

Elliott, R. (1989) Helpful and nonhelpful events in brief counselling interviews: an empirical taxonomy. Journal of Counseling Psychology. 32(3), 307-322.

Fawzy, F.L, Fawzy, N.W., Arndt, L.A. \& Pasnau, R.O. (1995) Critical review of psychosocial interventions in cancer care. Archives of General Psychiatry, $52(2), 100-113$.

Jones, E.E., Cumming, J.D. \& Horowitz, M.J. (1988) Another look at the nonspecific hypothesis of therapeutic effectiveness. Journal of Consulting and Clinical Psychology, 61(2), 306-16.

Kvale, S. (1996). InterViews. London: Sage.

Lambert, M. J. (1992) Implications of outcome research for psychotherapy integration. In: Norcross, J.C. \& Goldstein, M.R. (Eds) Handbook of psychotherapy integration. New York: Basic Books, pp. 94-129.

Lederberg, M.S. \& Holland, J.C. (2011) Supportive psychotherapy in cancer care: an essential ingredient of all therapy. Watson, M, \& Kissane, D. (Eds) 
Handbook of Psychotherapy in Cancer Care. Chichester: Wiley-Blackwell. pp. 3-14.

Llewelyn, S.P, Elliott, R., Shapiro, D.A., Hardy, G. \& Firth-Cozens, J. (1988) Client perceptions of significant events in prescriptive and exploratory periods of individual therapy. British Journal of Clinical Psychology 27, 105-114.

Luebbert, K., Dahme, B. \& Hasenbring, M. (2001) The effectiveness of relaxation training in reducing treatment-related symptoms and improving emotional adjustment in acute non-surgical cancer treatment : a meta-analytical review. Psycho-Oncology, 10, 490-502.

Macmillan Cancer Support

http://www.macmillan.org.uk/Cancerinformation/Cancertypes/Unknownprima ry/AboutCUP/Primarysecondarycancers.aspx [accessed on 13.02.13]

Manne, S.L., Rubin, S., Edelson. M., Rosenblum, N., Bergman, C., Hernandez, E., Carlson, J., Rocereto, T. \& Winkel, G. (2007). Coping and communicationenhancing intervention versus supportive counseling for women diagnosed with gynecological cancers. Journal of Consulting and Clinical Psychology, $75,615-628$.

Manne, S., Winkel, G., Zaider, T., Rubin, S., Hernandez, E. \& Bergman, C. (2010). Therapy processes and outcomes of psychological interventions for women diagnosed with gynecological cancers: a test of the generic process model of psychotherapy. Journal of Consulting and Clinical Psychology, 78, 236-248.

MacCormack, T., Simonian, J., Lim, J., Remond, L., Roets, Dunn, S. \& Butow, P. (2001) 'Someone who cares': a qualitative investigation of cancer patients' experience of psychotherapy. Psycho-Oncology, 10, 52-65 
Marcus, A.C., Garrett, K.M., Cella, D., Wenzel, L., Brady, M.J., Fairclough, D., PateWillig, M., Barnes, D., Powell Emsbo, S., Kluhsman, B.C., Crane, L., Sedlacek, S., \& Flynn, P.J. (2010). Can telephone counseling post-treatment improve psychosocial outcomes among early stage breast cancer survivors? Psycho-Oncology, 19, 923-932.

Mearns, D. \& Cooper M (2005) Working at Relational Depth in Counselling and Psychotherapy. London: Sage

Mooray, S., Greer, S. Bliss, J. \& Law, M. (1998) A comparison of adjuvant psychological therapy and supportive counselling in patients with cancer. Psycho-oncology, 7, 218-28

National Institute for Clinical Excellence (NICE) (2004) Improving Supportive and Palliative Care for Adults with Cancer: The Manual. London: National Institute for Clinical Excellence

Nezu, A.M., Nezu, C.M., Felgoise, S.H., McClure, K.S. \& Houts, P.S. (2003) Project Genesis: assessing the efficacy of problem-solving for distressed adult cancer patients. Journal of Consulting and Clinical Psychology, 71, 1036-1048

Page, A \& Stritzke, W. (2006) Clinical Psychology for Trainees: Foundations for Science-Informed Practice: Cambridge University Press: Cambridge.

Rogers, C. (1957) The necessary and sufficient conditions of therapeutic personality change. Journal of Consulting Psychology. 21(2), 95-103.

Watson, M., Denton, S., Balum, M., \& Greer, S. (1988). Counselling breast cancer patients: a specialist nurse service. Counselling Psychology Quarterly, 1, 2534. 


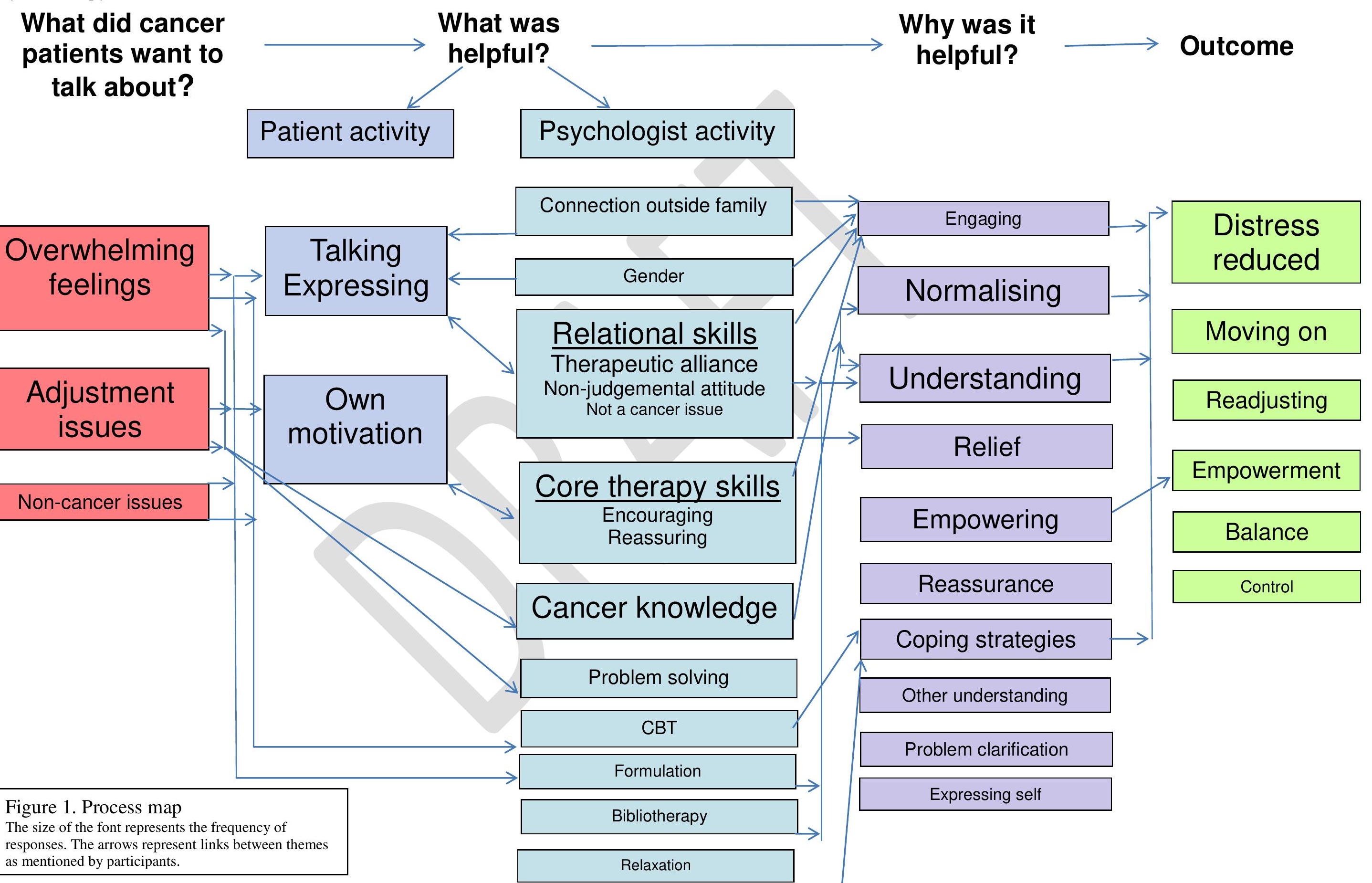




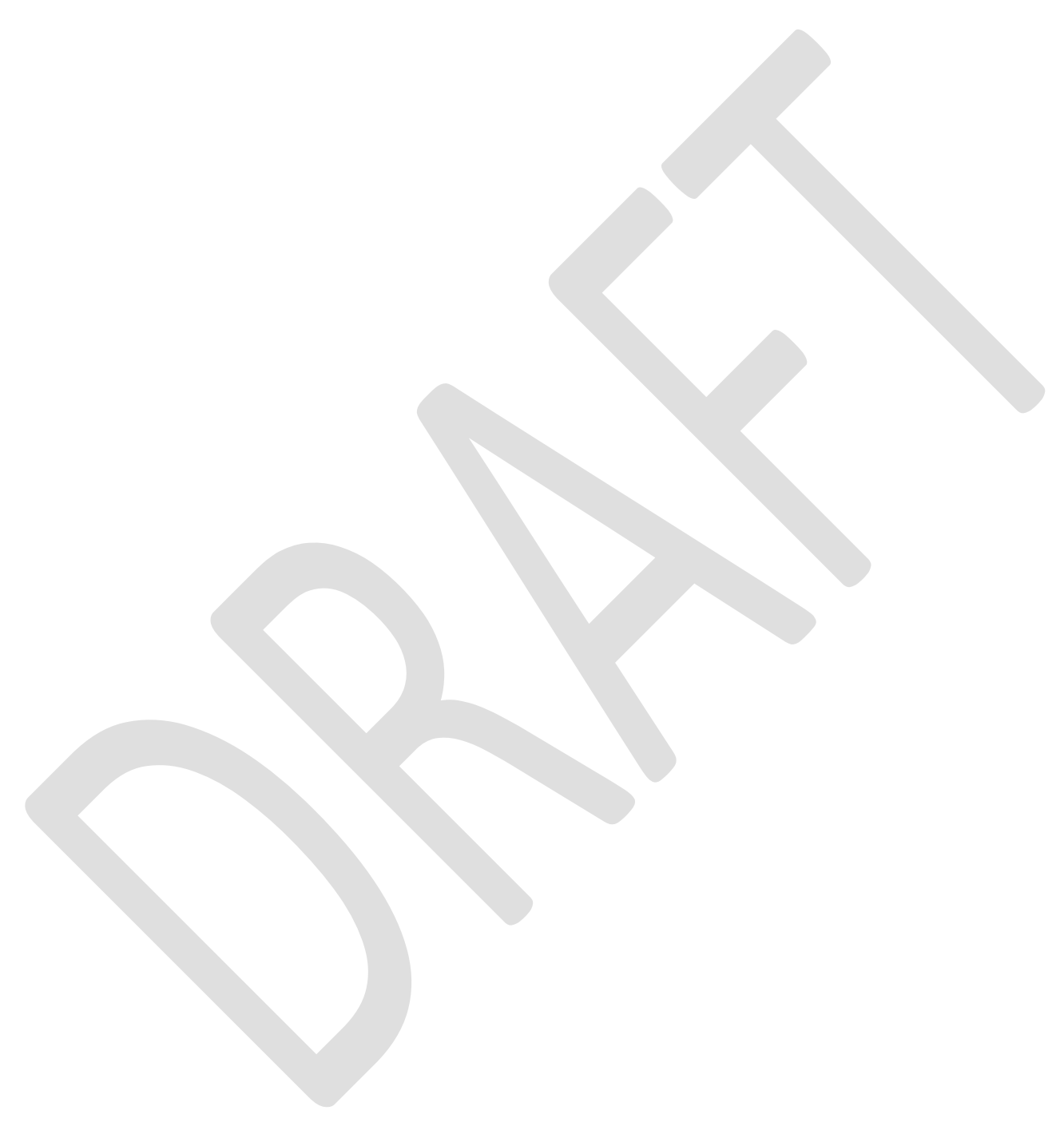


Omylinska-Thurston, J. \& Cooper, M. (in press) Helpful processes in psychological therapy with cancer patients. A qualitative interview study. Counselling and Psychotherapy Research

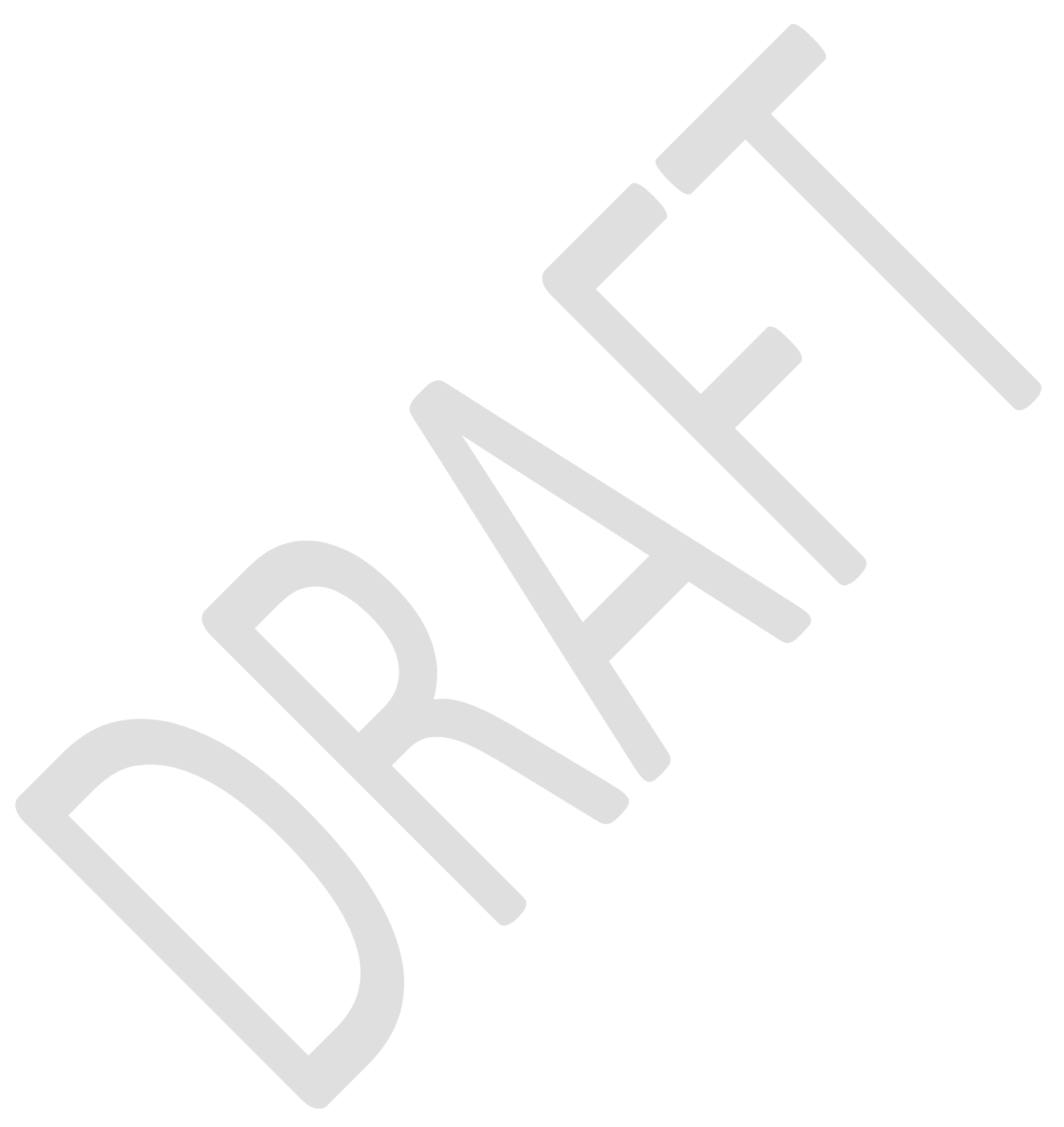




\begin{tabular}{|c|c|c|c|c|c|c|c|c|c|}
\hline \multicolumn{2}{|c|}{$\begin{array}{l}\text { What did cancer patients want to talk } \\
\text { about? }\end{array}$} & \multicolumn{4}{|c|}{ Helpful activities } & \multicolumn{2}{|c|}{ Why was it helpful? } & \multicolumn{2}{|c|}{ Outcome for the patient } \\
\hline \multirow{9}{*}{$\begin{array}{l}\text { Overwhelming feelings } \\
\text { Fear } \\
\text { Feeling low } \\
\text { Shame } \\
\text { Anger } \\
\text { Shock } \\
\text { Self-criticism }\end{array}$} & \multirow{9}{*}{$\begin{array}{l}8 \\
4 \\
4 \\
3 \\
3 \\
1 \\
1\end{array}$} & \multicolumn{2}{|c|}{ Patient activity } & \multicolumn{2}{|c|}{ Therapist activity } & & & & \\
\hline & & \multirow{8}{*}{$\begin{array}{l}\text { Talking } \\
\text { Expressing } \\
\text { About feelings } \\
\text { Talking through } \\
\text { Exploring } \\
\text { Reflecting }\end{array}$} & \multirow{8}{*}{$\begin{array}{l}8 \\
8 \\
4 \\
4 \\
4 \\
1\end{array}$} & Connection outside family & 5 & \multirow[t]{2}{*}{ Engaging } & \multirow[t]{2}{*}{4} & \multirow{2}{*}{$\begin{array}{l}\text { Dealing with } \\
\text { distress }\end{array}$} & \multirow[t]{2}{*}{8} \\
\hline & & & & \multirow{2}{*}{\multicolumn{2}{|c|}{$\begin{array}{ll}\text { Core therapy skills } & \mathbf{8} \\
\text { Reassuring } & 5 \\
\text { Encouraging } & 5 \\
\text { Listening } & 4 \\
\text { Asking questions } & 4 \\
\text { Reflecting back } & 4 \\
\text { Noticing } & 3 \\
\text { Acknowledging } & 1\end{array}$}} & & & & \\
\hline & & & & & & Normalising & 8 & $\begin{array}{l}\text { Moving on } \\
\text { Learning self-care skills } \\
\text { Relationships improved } \\
\text { Re-prioritising } \\
\text { Dealing with past issues }\end{array}$ & $\begin{array}{l}7 \\
7 \\
6 \\
2 \\
1\end{array}$ \\
\hline & & & & \multirow{9}{*}{$\begin{array}{l}\text { Relational skills } \\
\text { Therapeutic alliance } \\
\text { Non-judgemental } \\
\text { attitude } \\
\text { Treated not } \\
\text { as a cancer issue } \\
\text { Goals consensus/ } \\
\text { collaboration } \\
\text { Congruence } \\
\text { Empathy }\end{array}$} & \multirow{7}{*}{$\begin{array}{l}8 \\
6 \\
5 \\
\\
3 \\
3\end{array}$} & Understanding & 8 & & \\
\hline & & & & & & Relief & 7 & & \\
\hline & & & & & & Empowering & 7 & & \\
\hline & & & & & & Reassurance & 6 & & \\
\hline & & & & & & Coping strategy & & & \\
\hline \multirow{6}{*}{$\begin{array}{l}\text { Adjustment issues } \\
\text { Loss } \\
\text { Fear of cancer recurrence } \\
\text { Work issues } \\
\text { Body image } \\
\text { Communication with family }\end{array}$} & \multirow{6}{*}{$\begin{array}{l}8 \\
4 \\
4 \\
3 \\
2 \\
2\end{array}$} & Own motivation & 8 & & & \multirow[t]{2}{*}{ Other understanding } & \multirow[t]{2}{*}{4} & & \\
\hline & & & & & & & & \multirow{5}{*}{$\begin{array}{l}\text { Readjusting } \\
\text { Family communication } \\
\text { Going back to work } \\
\text { Going back to activities } \\
\text { Having "me" back } \\
\text { Thinking about future } \\
\end{array}$} & \multirow{5}{*}{$\begin{array}{l}6 \\
4 \\
2 \\
2 \\
2 \\
1\end{array}$} \\
\hline & & & & & 2 & \multirow{10}{*}{\begin{tabular}{|l|} 
Problem claritication \\
Expressing self \\
\end{tabular}} & 4 & & \\
\hline & & & & & & & 3 & & \\
\hline & & & & Cancer knowledge & 8 & & & & \\
\hline & & & & \multirow{2}{*}{ Problem solving } & \multirow[t]{2}{*}{5} & & & & \\
\hline \multirow{6}{*}{$\begin{array}{l}\text { Non-cancer issues } \\
\text { Childhood abuse } \\
\text { Relationship difficulties } \\
\text { Health anxiety } \\
\text { Panic attacks }\end{array}$} & \multirow{6}{*}{$\begin{array}{l}5 \\
3 \\
3 \\
3 \\
1\end{array}$} & & & & & & & Empowered & 6 \\
\hline & & & & Formulation & 3 & & & Balance & 6 \\
\hline & & & & Bibliotherapy & 3 & & & Control & 1 \\
\hline & & & & Relaxation & 2 & & & & \\
\hline & & & & Expressive activity & 1 & & & & \\
\hline & & & & Gender & 4 & & & & \\
\hline
\end{tabular}

Omylinska-Thurston, J \& Cooper, M. (in press) Helpful processes in psychological therapy with cancer patients: a qualitative interview study. Counselling and Psychotherapy Review 
Table 1. Domains, categories and sub-categories of helpful processes within therapy for cancer patients

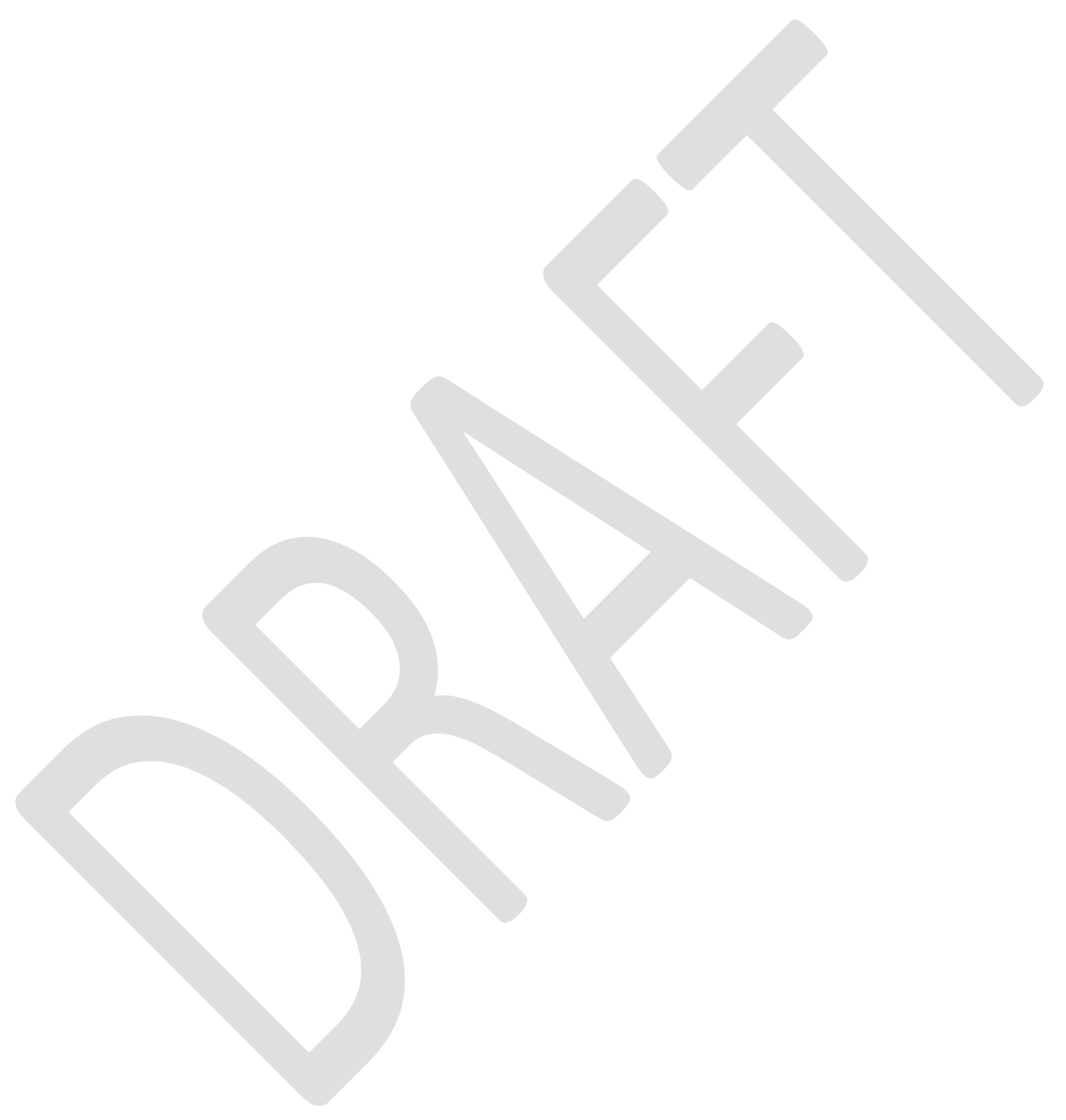

Omylinska-Thurston, J \& Cooper, M. (in press) Helpful processes in psychological therapy with cancer patients: a qualitative interview study. Counselling and Psychotherapy Review 